\title{
OBVLADOVANJE INFORMACIJ IN OMREŽNO SODELOVANJE V SLOVENSKI VOJSKI - NUJNO ALI LE AKTUALNO
}

\section{INFORMATION MANAGEMENT AND NETWORK COLLABORATION IN THE SLOVENIAN ARMED FORCES - A NECESSITY OR ONLY A TOPICAL ISSUE}

Povzetek Živimo v času, ko sta obseg in zapletenost informacij čedalje večja, zato postaja tudi področje celovitega obvladovanja informacij s finančnega vidika čedalje pomembnejše. Čedalje pomembnejše pa je tudi vprašanje urejanja obvladovanja informacij v SV. Učinkovit proces obvladovanja informacij mora zagotoviti, da so prave informacije $\mathrm{v}$ procesih na voljo tako, kot je treba. Kljub množici številnih tehnologij in aplikativnih rešitev obvladovanje informacij brez ustreznega obvladovanja dejavnikov organizacijske kulture in sodelovanja, delitve informacij ter obvladovanja informacijskih potreb ni mogoče pričakovati večje učinkovitosti procesov. Članek ugotavlja, da raven celovitega obvladovanja informacij pozitivno vpliva na raven učinkovitosti in hitrost izvajanja procesov. Med vplivnimi dejavniki izstopata obvladovanje informacijskih potreb in organizacijska kultura.

Ključne Obvladovanje informacij, upravljanje informacij, omrežno sodelovanje, procesi, besede portal.

Abstract We are living in the time in which the extent and complexity of information are increasing. As a result, the financial aspect of comprehensive information management is becoming more important. Furthermore, the information management in the Slovenian Armed Forces is acquiring an increasingly significant role as well. An effective information management process ensures that the right information is available as and when needed. Despite numerous technologies and applied solutions, we cannot expect a higher level of efficiency without the adequate management of aspects relating to organizational culture, cooperation, information sharing and information needs. The article determines that comprehensive information management has a positive impact on the level of effectiveness and speed of process execution. In this context information management and organisational culture are the most influential factors.

Information management, network collaboration, process, portal. 
Uvod Med ekonomsko krizo in zmanjševanjem proračunskih sredstev se organizacije spopadajo z izzivom, kako kratko- in dolgoročno z uporabo sedanjih tehnologij izboljšati podporo uresničevanju ciljev organizacije. Tudi v Slovenski vojski (SV) se srečujemo z množico informacijskih sistemov, ki pogosto niso ustrezno izkoriščeni in povezani, da bi omogočali izmenjavo informacij za uspešno sodelovanje udeleženih $\mathrm{v}$ procesu, ki je nujno, če želimo biti učinkoviti. Če transformacija sistemov poteka brez temeljitih analiz procesov, delovnih tokov in informacijskih potreb udeleženih v njih, ni mogoče pričakovati višje stopnje izkoriščenosti informacijskih tehnologij kljub uvajanju novih tehnoloških rešitev. Področje obvladovanja informacij danes bistveno presega že davno uveljavljen proces upravljanja dokumentov. Obseg, različnost in zapletenost podatkov, ki prihajajo v organizacijo, nikoli niso bili večji. Ustrezna organizacija, kakovost in učinkovitost obvladovanja informacij so tudi v SV bistven vzvod organizacije za odzivanje na pritiske sodobnega časa.

Informacije se danes pojavljajo v najrazličnejših oblikah (simulacijski modeli, kratki filmi, kratka sporočila, kratke objave in sporočila na socialnih omrežjih), kar vodi k zahtevi po njihovem obvladovanju in usmerjanju za največjo korist organizacije.

Natova doktrina (Nato Joint doctrine for information management - JDN IM, 2006) poudarja, da je za uresničevanje ciljev obvladovanja informacij pomembna jasnost zahtev po informacijah. Te so opredeljene kot del procesa načrtovanja, s katerim se izrazi nameravana aktivnost oziroma učinek te aktivnosti. Je aktivnost $\mathrm{v}$ posameznem procesu ali dejavnosti, s katero je izraženo, kje, kdaj in zakaj je neka informacija nujna. Te informacije so tudi del arhitekture sistemov. V razmerah, $\mathrm{v}$ katerih informacijske storitve temeljijo na posameznih tehnoloških rešitvah, ne na skupni informacijski arhitekturi, je učinkovit dostop do informacije uporabniku pogosto še vedno zelo otežen.

Celovito obvladovanje informacij je zaradi novih tehnologij ter velike količine informacij zelo zapleteno in obsežno področje. Avtorji ugotavljajo, da za uspešno delovanje organizacije informacijska tehnologija ni dovolj, saj je treba obvladovati informacijo v celotnem življenjskem ciklu, z informacijsko tehnologijo ali brez nje. Kljub velikim investicijam $\mathrm{v}$ tehnologijo zaradi spreminjajočega se okolja še ni garancije, da bo ustrezna informacija tudi pravočasno na voljo.

V članku analiziramo obvladovanje informacij v SV in ga primerjamo z drugimi organizacijami. V SV je področje normativno urejeno od leta 2010 z Direktivo za upravljanje $\mathrm{z}$ informacijami ${ }^{1}$. Na tej podlagi je bil leta 2013 formalno ustanovljen oddelek za upravljanje informacij, kar je nujen formalni korak za razvoj področja. Normativna ureditev seveda še ne pomeni uspeha v praksi, saj neustrezno razlikovanje informacije in informacijske tehnologije povzroča napetosti med nosilci tehnologije

\footnotetext{
Angleška beseda Information management je bila v SV leta 2010 prevedena kot upravljanje z informacijami (upravljanje informacij). Pozneje se je začel uporabljati prevod obvladovanje informacij, ki področje obsega bolj celovito.
} 
in nosilci procesov. Področje informacijske tehnologije tako še vedno prevzema področje vsebin, ob tem pa ne daje celovite podpore izvajalcem procesov. Področji obvladovanja informacij in informacijske tehnologije sta tesno povezani in drugo brez drugega ne moreta delovati.

Uvedba celovitega obvladovanja informacij v SV, le zaradi aktualnosti, ne more dati optimalnih rezultatov, če je uvedba elementov zmogljivosti področja (obvladovanje informacij, organizacijska struktura, organizacijska kultura in infrastruktura, usposobljenost kadra in uveljavljenost metod razvrščanja) pomanjkljiva.

Obvladovanje informacij je $\mathrm{v}$ Natu in drugih organizacijah, ki sledijo težnjam na področju obvladovanja informacij, sestavljeno iz varnostne politike, politike obvladovanja informacij, obvladovanja znanja, standardov, metapodatkov in taksonomij, med najpomembnejšimi. SV ima še veliko priložnosti, da razvije področja obvladovanja znanja ter uvedbe taksonomije in metapodatkov. Sprejeti bi bilo treba tudi standarde informacij (oblika informacij), saj je signirni načrt kot del normativne ureditve pregrob za učinkovito iskanje. Obvladovanje znanja ostaja na ravni zamisli. Normativne podlage, kot so komunikacijski načrt enot za obvladovanje informacij in pregledi informacijsko-komunikacijskih sistemov ter procesov, ki so namenjene izboljšavam, se uresničujejo le izjemoma. Področje varovanja informacij zahteva urejeno politiko dostopov skladno z normativno ureditvijo in politiko dostopov glede na potrebe po vedenju.

\section{TEORIJA IN PRAKSA OBVLADOVANJA INFORMACIJ}

Obvladovanje informacij vključuje ljudi, procese in tehnologijo, kar je danes tesno povezano z omrežnim sodelovanjem. Souporaba informacij je imperativ za učinkovito doseganje ciljev organizacije.

Nato je v podporo učinkovitemu odločanju oblikoval pobudo za spremembe pri obvladovanju informacij, s čimer naj bi se zagotovile prave informacije pravim ljudem, ob pravem času in v pravi obliki (Van Domselaar, 2010).

\subsection{Pojmovanje obvladovanja informacij}

Današnje organizacije razumejo informacije kot pomemben vir, na primer finančni ali materialni ipd. Primerno obvladovanje in uporaba informacije ustvarjata dodano vrednost s prepoznavnimi učinki. Organizacije, ki gledajo v prihodnost, obravnavajo informacije kot strateški vir, ki jim omogoča ustvarjati strateško prednost.

Vsak model obvladovanja informacij mora, kot menijo Lindermann in soavtorji (2005), vključiti kritične elemente, kot so ljudje in njihove vloge ter procesi in tehnologije za uvedbo (slika 1). K zagotovitvi kakovostnih informacij in njihove uporabnosti v procesih bistveno prispeva tudi struktura informacij. 
Butler (2006) opozarja na pametnejšo uporabo informacij po načelu »naredi enkrat in večkrat uporabi, pri tem pa se izogibaj prenasičenju informacij in daj podatke tja, kjer so potrebni, ne pa povsod $\ll$.

Slika 1:

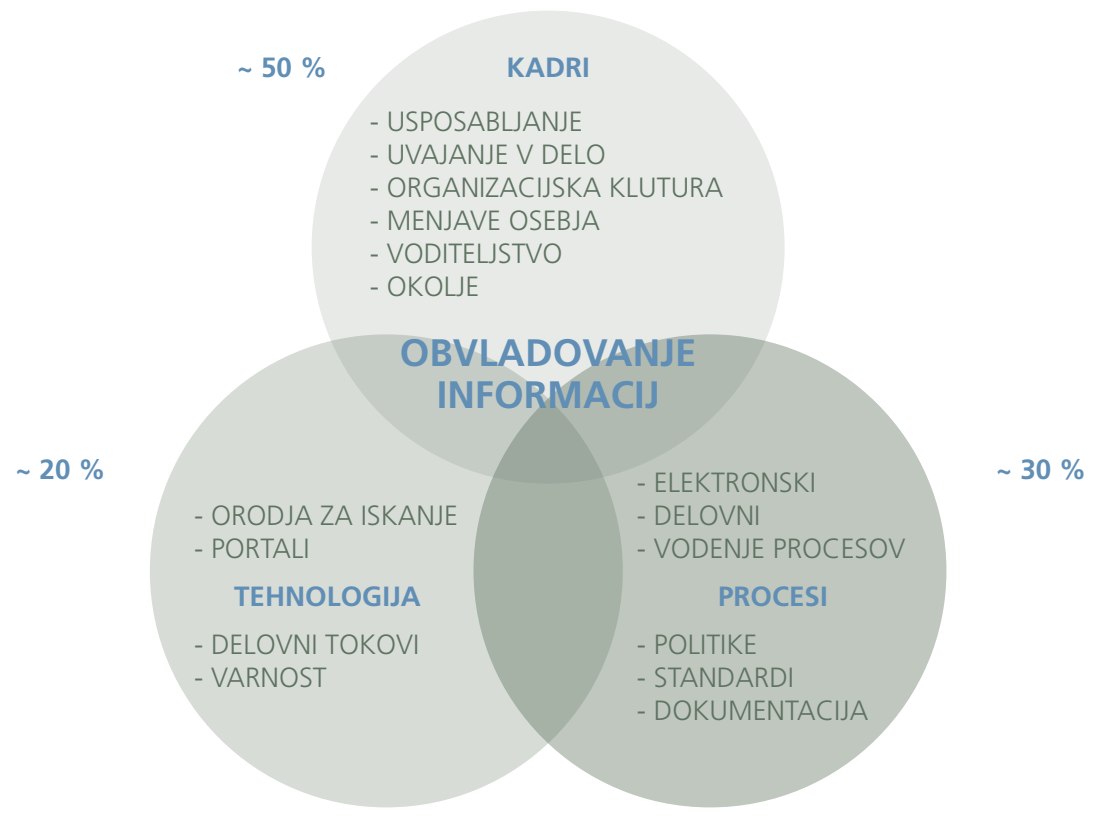

Linderman in soavtorji (2005) izpostavljajo poseben pomen dejavnosti razglasitve standardov, nadzora informacij, zagotavljanja, zbiranja, razširjanja in upravljanja informacij ter njihovega umika ali uničenja. Louwe in soavtorji (2010) namreč ugotavljajo, da je informacija najdragocenejše sredstvo organizacije, vendar so podatki povsod, in sicer $\mathrm{v}$ velikih količinah, ker so podvojeni, nasprotujoči si, nedostopni, nenadzorovani, netočni, brez pomena ali skriti v aplikacijah.

Disciplina obvladovanja informacij se deli na obvladovanje informacij z vidikov poslovanja in informacijske ter komunikacijske tehnologije. Poslovni vidik obravnava informacijo kot pomemben vir, tehnološki pa predvsem tehnološka vprašanja obdelave podatkov, pri čemer je vidik obvladovanja informacijske tehnologije preveč poudarjen, seveda na škodo obvladovanja informacij (Davenport in Prusak, 2000).

Izmenjava informacij in še posebno njihova souporaba sta tesno povezani $\mathrm{z}$ organizacijsko kulturo, ki takšno obnašanje spodbuja ali ovira, kar še otežuje vprašanje organizacijske umestitve obvladovanja informacij. 
Organizacijska kultura je po Natovi doktrini (JDN IM, 2006) oblikovanje odnosa do vrednotenja, posredovanja, varovanja in ohranjanja informacij, skupaj z razvojem znanja posameznika in skupin.

Gurteen (1999) opozarja, da pomeni souporaba informacij drugačno videnje sveta, ki pa je izvedljivo le ob zavedanju uporabnikov, da jim tak način pomaga delo opraviti učinkoviteje. Wortel in drugi (2007) pa govorijo o dejavnikih, ki vplivajo na souporabo informacij v organizaciji in ugotavljajo, da kulturološki dejavniki, kot so organizacijska in informacijska kultura in drugi, precej vplivajo na odnos do souporabe informacij. Sociološki vidik opredeljuje vrednote, prepričanja in kulturo, iz česar je mogoče sklepati, da je razvoj kulture souporabe informacij bolj vprašanje vodenja kot pa informacijske tehnologije (McNulty, 2004).

Proces obvladovanja znanja pomaga znanje ustvariti, razširiti in porazdeliti. Obvladovanje znanja je zelo pomembno z vidika obvladovanja informacij, obsega pa pot od zbiranja podatkov do znanja za podporo odločanju.

Velika količina podatkov nima dodane vrednosti, če iz njih ne pridobimo znanja. General Mattis (Call, 2009) ugotavlja, da je znanje oborožitev, ki jo uporabljamo vsakodnevno.

Call (2009) tudi ugotavlja, da velike količine podatkov in informacij same po sebi še ne pomenijo dodane vrednosti. Obvladovanje znanja vodi od podatka prek informacije do znanja, po korakih od identifikacije, ustvaritve, predstavitve ter omogočanja dostopa do usposobljenosti. Različne vire znanja je treba ustvariti tako, da jih bo mogoče analizirati, oblikovati in razvijati.

\section{2 Življenjski cikel informacije in proces}

Obvladovanje informacij $\mathrm{v}$ povezavi $\mathrm{z}$ ljudmi in tehnologijo $\mathrm{v}$ organizaciji je dejavnik, pri katerem napake slabijo delovanje organizacije. Organizacija lahko oslabi tudi zaradi tekme med notranjimi skupinami, ki so posledica pomanjkanja skupnega razumevanja, povzročenega z napačnim pretokom informacij. Organizacija tako ne zna več črpati strokovnega znanja svojih članov in kljub dobri tehnološki opremljenosti ter dobrim namenom sprejema slabe odločitve. To so nekateri znani simptomi, povezani s slabim obvladovanjem informacij. Orodja in viri informacij sicer lahko $\mathrm{v}$ teh razmerah pomagajo, vendar morajo biti zasnovani in razviti $\mathrm{s}$ širšim razumevanjem, kako se informacije v organizacijah ustvarjajo in uporabljajo (Choo, 1997). 
Slika 2:

Cikel obvlado-

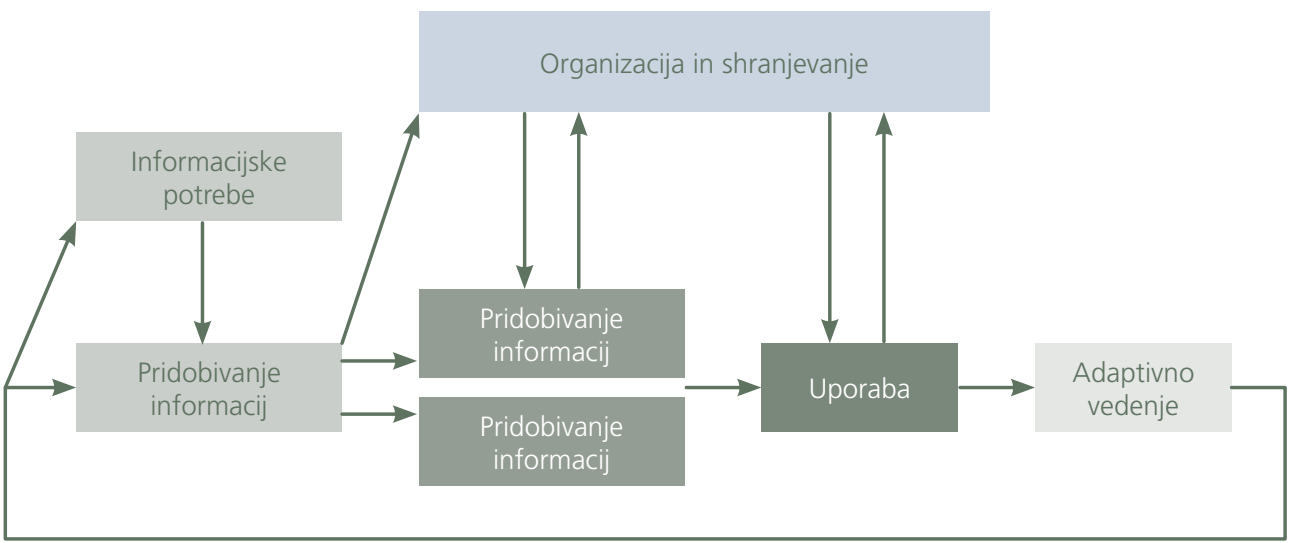

Cikel obvladovanja informacij

Choo (2002) je prikazal obvladovanje informacij kot cikel šestih med seboj povezanih aktivnosti, ki delujejo hkrati z aktivnostmi učenja $\mathrm{v}$ organizaciji (identifikacija informacijskih potreb, pridobivanje informacij, organizacija informacij in hranjenje, razvoj informacijskih produktov in storitev, distribucija in uporaba informacij) in jih podpirajo (slika 2). Proces se vedno začne na desni strani, s prilagoditvijo organizacije. Namen sistema je, da uporabnikom zagotavlja ustrezne informacije.

\subsection{Organizacija obvladovanja informacij}

Oseba, pooblaščena za obvladovanje informacij, ima veliko povezovalno vlogo med procesi, ljudmi in informacijsko tehnologijo. Sodeluje pri nadzoru obvladovanja informacij v celotnem življenjskem ciklu informacije, od pridobitve, uporabe, odlaganja do arhiviranja in vpliva na to, kako natančno in varno ter učinkovito in dobro se prenašajo informacije. Niti eno področje nima možnosti za izpolnitev svojega cilja, če nima neposrednega dostopa do najnovejših in najnatančnejših informacij (Leigh, 2012).

\subsection{Procesi in informacijske potrebe}

Organizacijske enote in posamezniki v SV se pri vsakodnevni poplavi informacij in v želji po njihovem čim učinkovitejšem obvladovanju različno organizirajo. Pogosto sledijo svojim navadam, saj prilagajanje novim zahtevam nikoli ni preprosto. Poplava informacij, slaba obveščenost o dostopnih informacijah, pomanjkanje poznavanja tehnologij ter kakovostnega procesa obvladovanja informacij povzročajo daljše procesne cikle in večje stroške posameznega procesa. 
Zahteva po informaciji je opredeljena kot del načrtovanja znotraj posameznega procesa ali dejavnosti, s katero izrazimo, zakaj, kdaj in kje potrebujemo zahtevano informacijo. Če je aktivnost vezana na proces, ta običajno zahteva sodelovanje udeležencev v procesu pri izmenjavi informacij (Dovč, 2013).

Po Natovi doktrini je obvladovanje informacije proces, ki podpira učinkovito izkoriščanje informacij in skupno razumevanje situacije. Povezuje infrastrukturo, v kateri so informacije na voljo in ki omogoča njihovo uporabo, kar vodi $\mathrm{k}$ razumevanju informacij, odločanju in ukrepanju. Vsebuje tri dele (slika 3): določanje informacijskih potreb, obvladovanje toka informacij in administracijo informacij (postavitev organizacijske strukture, vlog, odgovornosti in pristojnosti posameznika v procesu).

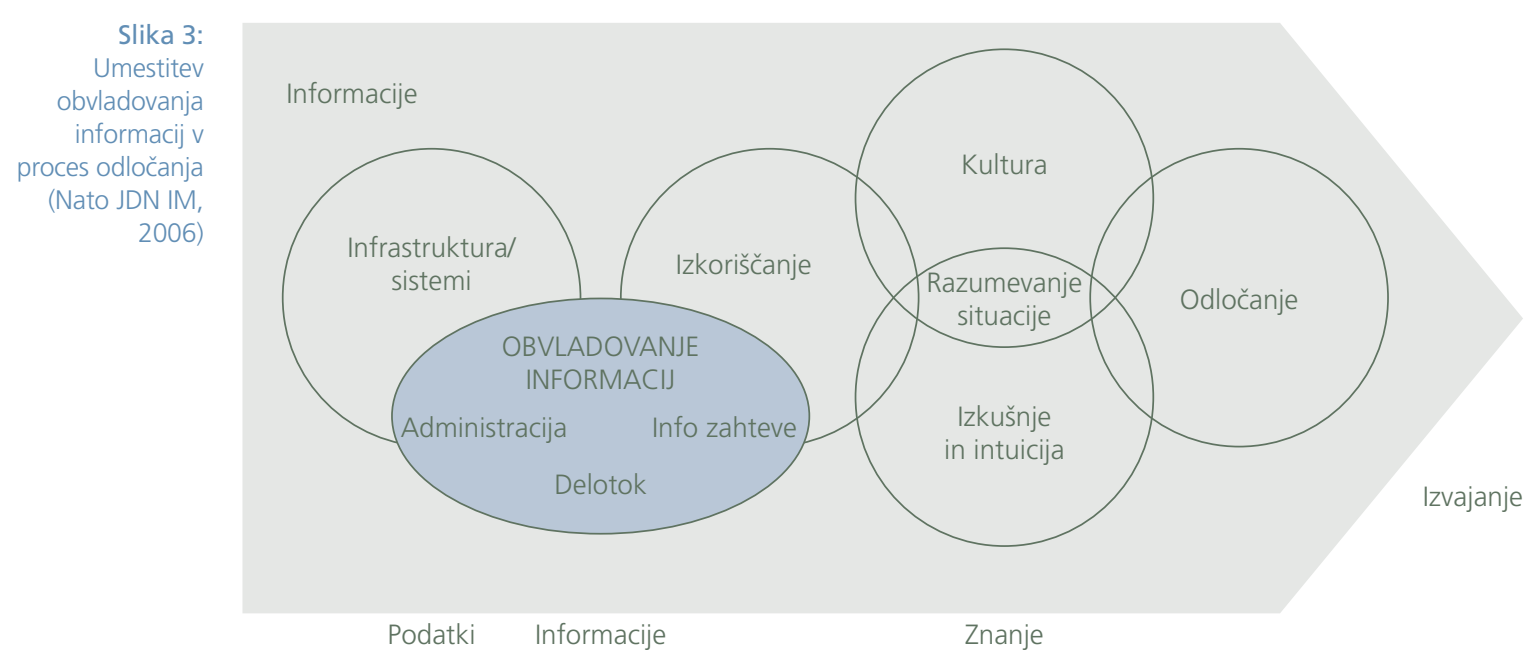

Pontius in Whitehead (2010) ugotavljata, da se, če ne sledimo procesom, kljub dobri tehnologiji in omrežjem, učinkovitim politikam, rešenim vsem tehničnim vprašanjem in ustreznim postopkom ne moremo izogniti negativnim posledicam.

Obvladovanje procesov in njihovo načrtovanje ali modeliranje sta pomemben del določanja informacijskih potreb, na podlagi katerih je mogoče vzpostaviti kakovostne informacijske rešitve in obvladati informacije v življenjskem ciklu.

Po Natovi doktrini informacije v omrežju klasificiramo z metapodatki po vnaprej pripravljeni standardni specifikaciji. S tem sta omogočena hitro iskanje znotraj repozitorijev in vsebin v omrežju ter njihova ponovna uporaba. Klasifikacija pomaga pri opredelitvi informacij in vsebin v omrežju, s čimer uporabniki dobijo informacijo, opredeli pa tudi, komu so informacije namenjene, kakšen je njihov obseg in 
kakšni so pogoji za spreminjanje informacij in vsebin v omrežju. Metapodatki so ključni element za učinkovito izmenjavo informacij, zato je treba določiti osnovne metapodatkovne elemente za opisovanje in kategorizacijo informacij.

\subsection{Tehnologija}

Organizacije uporabljajo za sodelovanje številne tehnologije, ki so pogosto prepuščene uporabnikom in njihovi iznajdljivosti, da si z njimi pomagajo pri opravljanju nalog. Poleg tega tehnologije med seboj niso integrirane, kar otežuje izmenjavo informacij. S tem vprašanjem se sooča tudi SV. Celovitost obvladovanja informacij je pomemben dejavnik pri izboljšanju izkoriščenosti informacij.

Infrastruktura po JDN IM 82006 zagotavlja uvajanje, podporo in vzdrževanje ustrezne strojne in programske opreme ter omrežij za pridobivanje, shranjevanje in posredovanje informacij.

Louwe in soavtorji (2010) ugotavljajo, da je zelo verjetno, da brez dobro oblikovane informacijske arhitekture, ki nam pomaga pri kategorizaciji in organizaciji vsebin, ne bo mogoče pridobiti uporabne informacije niti iz sicer uporabnih podatkov.

Povezovalne zmogljivosti, ko se podatki izmenjujejo med različnimi sistemi, v katerih so že na voljo v podporo izvajanju neke dejavnosti, zahtevajo tudi višjo raven opredeljenosti procesov in informacijskih zahtev. Te spremembe lahko še dodatno vplivajo na način obvladovanja informacij in razvoj informacijske arhitekture.

Obvladovanje informacij je po mnenju Robertsona (2005) mnogo več, kot le informacijska tehnologija. Enako pomembni so poslovni procesi in prakse, ki podpirajo ustvarjanje, oblikovanje in uporabo podatkov.

Po direktivi MO (2010) morajo informacijski in komunikacijski sistemi in storitve omogočati visoke standarde dostopanja, varovanja ter uporabe arhitekture. Uresničitev teh ciljev v doseženi stopnji obvladovanja informacij je še zelo odmaknjena, kar je spodbuda za temeljitejšo analizo obvladovanja informacij. Stanje, ko področje informacijsko-komunikacijske tehnologije prevzame področje obvladovanja informacij in je uresničen le element tehnologije, se kaže v razkoraku med potrebami procesov in uporabnikov po eni ter podporno tehnologijo po drugi strani.

\subsection{Omrežno sodelovanje}

Koncept omrežnih storitev predstavlja tehnologije, ki na različnih ravneh spodbujajo sodelovanje med uporabniki oziroma udeleženci v omrežju.

Po mnenju Naglja (2011) s pojmom omrežno sodelovanje razumemo delovanje dveh ali več entitet, ki naj bi imele skupni namen. Sodelovanje se dogaja v kognitivni domeni in zahteva sposobnost izmenjave informacij. Današnje tehnologije omogočajo sodelovanje tudi, ko sodelujoči niso v istem prostoru. 
Spletni portal MO in SV velja za točko dostopa do informacij v omrežju, vendar ni samo vmesnik za dostop do informacij, temveč je postal sinonim za tehnologije v podporo skupinskemu delu. Vsebuje številne možnosti za sodelovanje in ga zaposleni uporabljajo za doseganje skupnih ciljev. Informacije na portalu morajo biti organizirane, da so uporabne, obvladovanje informacij pa ima ravno na tem področju niz priložnosti za napredek pri njihovem strukturiranju oziroma organizaciji, kar pomeni znanje organizacije in izboljšanje sodelovanja $\mathrm{z}$ učinkovito distribucijo in izmenjavo informacij.

Uporabniki iščejo informacije na portalu zato, da opravijo svoje aktivnosti, pa naj bo to samostojno ali v sodelovanju s sodelavci. Tehnologije za skupinsko delo omogočajo številne možnosti oblikovanja, obdelave in uporabe informacij.

Zmogljivosti omrežnih tehnologij omogočajo vedno nove koncepte uporabe. Med pomembnejše spada koncept storitvene arhitekture, ki omogoča učinkovitejše povezovanje informacijskih rešitev in hitrejše prilagajanje spremembam $\mathrm{v}$ procesih. Bistveni del sprememb so socialni mediji, ki prinašajo drugačne oblike individualnega komuniciranja, predvsem celovito analiziranje, ki z analitičnimi tehnologijami prispeva kakovostne analize napovedovanja in jasnejše slike kljub veliki količini podatkov. Ti novi koncepti in tehnologije po trditvi Naglja (2011) omogočajo, da so informacije v kratkem času dostopne večji množici uporabnikov. Vse pa v bistvu omogočajo boljšo informiranost in zato boljše sodelovanje. Vse pomembnejše postaja tudi to, kako naj organizacije preoblikujejo obvladovanje informacij, da bodo uspešno izkoriščale te novosti.

\section{METODOLOGIJA IN OPIS RAZISKAVE}

Namen raziskave je bil analizirati dejavnike, ki vplivajo na pripravljenost in sposobnost za izmenjavo informacij prek sistemov poveljevanja in kontrole, ter operativne procese, kar je pomembna vloga celovitega obvladovanja informacij. Raziskava je bila zastavljena s temeljnimi vprašanji o ključnih elementih celovitega obvladovanja informacij v SV in njihovem vplivu na delovanje procesov.

\subsection{Metodologija raziskave}

Izhodišče raziskave so izkušnje in rezultati intervjuja o zadovoljstvu uporabnikov pri uporabi tehnologij za sodelovanje na skupnem informacijskem portalu. Variable raziskovalnega modela (slika 4) izhajajo iz metodologije vrednotenja zrelosti obvladovanja informacij Natovega zrelostnega modela (Nato information capability maturity model, 2007) in strokovnih člankov drugih avtorjev.

$Z$ raziskavo smo iskali odgovore na vprašanje o medsebojnih vplivih temeljnih elementov celovitega obvladovanja informacij in procesov v SV. Številne dejavnike obvladovanja informacij smo s predhodno analizo omejili na obvladovanje informacijskih potreb, standarde informacij, proces obvladovanja informacij ter organizacijsko strukturo in kulturo, predvsem $\mathrm{z}$ vidika sodelovanja. 
Opredelitev variabel zrelosti obvladovanja informacij in operativnega tempa

1. Zrelost obvladovanja informacij $(\mathrm{ZOI})^{2}$ je stopnja obvladovanja informacij, ki izhajajo iz metodologije zrelosti njihovega obvladovanja. Kritični elementi so:

- integralnost: opremljenost informacij z dodatnimi podatki (lažje iskanje);

- organizacijska kultura: kako se souporaba informacij kaže v zadovoljstvu in osebnem razvoju, sodelovanje s posamezniki v drugih organizacijskih enotah in usposabljanje za uporabo navodil za pripravo operativnih postopkov in izmenjavo informacij v informacijskem okolju;

- informacijske potrebe: obseg pregledovanja kritičnih informacijskih zahtev in procesov za uresničevanje poslanstva ter odgovornost posameznika za delo $\mathrm{z}$ informacijami;

- organizacija: odgovornost za obvladovanje informacij v organizaciji in obseg uporabe komunikacijskega načrta za distribucijo in izmenjavo informacij, opredeljenost procesov za delovni tok aktivnosti procesov, v kakšnem obsegu so uvedena navodila za souporabo informacij in souporaba dostopnih pravic;

- standardiziranost: pregled in identifikacija standardov obvladovanja informacij glede na informacijske potrebe za temeljne postopke enote.

2. Operativni tempo $(\mathrm{OT})^{3}$ je dimenzija časa pri izvajanju procesov oziroma hitrost izvajanja procesov. Je pokazatelj zmogljivosti uresničevanja osnovnih nalog in hkrati eden izmed parametrov procesov, ki je najbolj kritičen v vojaški strukturi. Kritični elementi so:

- kakovost procesov: kakovost informacij, ki nastajajo med delom na portalu z vidika točnosti, pomena za delo, števila podvojenih dokumentov, nelogičnih povezav med informacijami in zastarelosti; kako dobro rezultati procesov v povezavi s portalom zadovoljujejo pričakovanja uporabnikov produktov in kako dobro vmesni izdelki podprocesov ustrezajo zahtevam naslednje faze v procesu;

- stroški procesa: vpliv informacij na portalu na učinkovitost dela $\mathrm{v}$ organizacijski enoti;

- čas procesa: vpliv izmenjave informacij na portalu na hitrost dela.

Za izvedbo smo postavili hipotezo $\mathrm{H} 1$ : raven celovitega obvladovanja informacij vpliva na raven učinkovitosti izvajanja procesov.

Podatki so bili zbrani z vprašalniki v anketah in neposredno iz zapisov o uporabi podatkov v informacijskih sistemih. Opravljeni sta bili dve anketi, in sicer med uporabniki v rednem operativnem delu, od 100 povabljenih se jih je odzvalo 53, in med uporabniki pri eksperimentu, med katerimi je na anketna vprašanja odgovorilo 22 uporabnikov. Skupina anketiranih pri eksperimentu je bila izpostavljena dodatnim ukrepom obvladovanja informacij, saj je bil uporabniški proces opredeljen na višji ravni zrelosti, opredeljeni so bili informacijski standardi, povečan pomen njihovega sodelovanja in dodane nove storitve informacijske tehnologije.

2 Atributi ZOI so vzeti iz zrelostnega modela obvladovanja informacij v Natu.

3 Operativni tempo je vojaški termin za proces in pomeni hitrost izvajanja naloge. 


\subsection{Rezultati raziskave}

Analiza rezultatov anket in uporabe informacij je pokazala, da je stopnja obvladovanja informacij sorazmerno majhna glede na lestvico ocen od 1 do 7.

Pri zrelosti obvladovanja informacij so anketirani visoko ocenili zadovoljstvo z možnostjo delitve oziroma souporabe informacij (5,37), svojo odgovornost za informacije $(4,26)$ in sodelovanje tako znotraj oddelkov kot med funkcijami $(5,11)$. Posebno slabo pa so ocenili odgovornost za obvladovanje informacij $(2,60)$, kar največkrat pomeni posameznika, ki to delo opravlja del svojega delovnega časa. Nizko so ocenjeni tudi usposobljenost $(2,88)$, komunikacijski načrt $(2,94)$ in standardi informacij $(2,62)$, kar je skupaj s slabo opredelitvijo procesov $(2,81)$ mogoče vzrok za nižje ocene za obvladovanje informacij. Odgovorna oseba za obvladovanje informacij ni imenovana ali pa je imenovana le za del delovnega časa. Opredeljenost procesov kaže, da so ti opredeljeni predvsem na ravni oddelkov oziroma normativno v standardnem operativnem postopku. Celovito obvladovanje kakovosti je stvar organizacijskih rešitev.

Koncept omrežnega sodelovanja smo merili predvsem s številom odloženih in uporabljenih informacij. Oba parametra sta bila pridobljena iz devetmesečne zgodovine uporabe portala anketirane osebe. Povprečna ocena števila dostopov do informacij je še vedno pred oceno števila odloženih informacij. Zelo visoko so anketirani ocenili pomen sodelovanja zaradi uresničitve skupnega cilja $(4,73)$, veliko je tudi število dostopov $(4,24)$ in odloženih dokumentov $(3,86)$.

Operativni tempo je skupina spremenljivk, ki prikazuje učinek na uspešnost uresničevanja ciljev in učinkovitost delovnih procesov. Zelo visoko so ocenjene vse spremenljivke. Zlasti dobri sta oceni hitrosti procesa zaradi izmenjave informacij prek portala $(5,20)$ in učinkovitosti dela $(4,86)$, visoko je ocenjeno tudi število podvojenih dokumentov $(5,00)$, kar je povezano s poznejšo soodvisnostjo z uporabo storitev. Več avtomatiziranih storitev je uporabljenih, manj je možnosti, da bi se dokumenti podvajali.

V raziskavi s hipotezo H1 smo želeli odgovoriti na vprašanje, ali raven celovitega obvladovanja informacij pozitivno vpliva na raven učinkovitosti procesov.

Pri zrelosti obvladovanja informacij je najpomembnejša soodvisnost od operativnega tempa pri kakovosti procesov, ki je odvisna od integralnosti $\left(0,520^{*}\right)$, informacijskih potreb $\left(0,400^{*}\right)$, organizacije $\left(0,445^{*}\right)$ in standardiziranosti informacij $\left(0,479^{*}\right)$ (Dovč, 2013, str. 58, tabela 15). Stroški procesov so odvisni od integralnosti $\left(0,519^{*}\right)$, organizacijske kulture $(0,419)$, organizacije $\left(0,490^{*}\right)$ in standardiziranosti informacij (0,533*) (Dovč, 2013, str. 57, tabela 13). Soodvisnost z informacijskimi potrebami obstaja, vendar ni signifikantna, čas procesov pa je odvisen od organizacije $\left(0,488^{*}\right)$ in standardiziranosti informacij $\left(0,473^{*}\right)$. Soodvisnost obstaja tudi z integralnostjo, organizacijsko kulturo in informacijskimi potrebami, vendar ni signifikantnosti (Dovč, 2013, str. 54, tabela 11). 


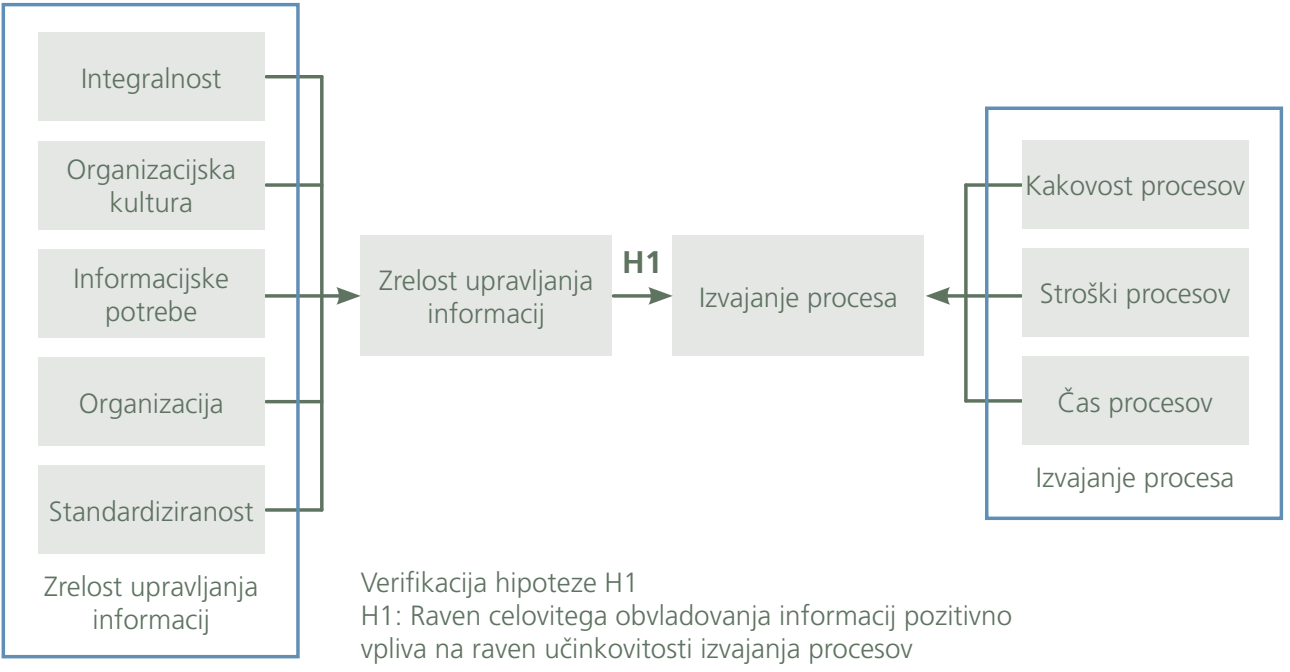

Raziskavaje potrdila hipotezo $\mathrm{H} 1$ : raven celovitega obvladovanja informacij pozitivno vpliva na raven učinkovitosti procesov, saj je celovito obvladovanje informacij močno soodvisno z operativnim tempom $\left(0,445^{* *}\right)$ pri stopnji signifikantnosti 0,01 na signifikantnost 0,001 (Dovč, 2013, str. 58, tabela 14).

\section{RAZPRAVA}

Analiza je pokazala na številna problemskega stanja in dejavnike, ki so vzroki ali posledice v praksi dosežene zrelosti obvladovanja informacij v SV. Iz tega izhajata majhna podpora procesom in potrebam njihovih izvajalcev ter zato povečan obseg dela.

Glavna težava je v slabi prepoznavnosti obvladovanja informacij v SV. Pri uresničevanju omejitev potreb po vedenju in deljenju oziroma izmenjavi informacij se to kaže v nepopolnih in nepravilnih informacijah in zato ne najboljših odločitvah. Za prakso obvladovanja informacij je značilen rezultat splošno nizke kulture souporabe in delitve informacij, ki ima številne posledice. Med njimi so daljši časi izvedbe, nizka raven uporabe informacijsko-komunikacijskih rešitev in stroški procesov.

Anketa med posameznimi uporabniki je pokazala niz odprtih vprašanj, na katera odgovori niso preprosti, splošno reševanje prek uveljavljenih pravil organizacije pa ne kaže vedno pravih učinkov.

Med večje dejavnike spada raven zrelosti obvladovanja poslovnih procesov. Večinoma so procesi določeni na nižji ravni, v obliki navodil in postopkov, kar dopušča različne razlage in ravnanja. Ob pogostih kadrovskih premikih je težava še 
bolj prepoznavna in se kaže v času, v katerem se posameznik na novem delovnem mestu vključi v delovne procese. Njegova uspešnost je odvisna tudi od sposobnosti hitrega iskanja informacij.

Obvladovanje taksonomij in metapodatkov je področje, ki še ni našlo pravega prostora v SV. Slabo zavedanje pomena klasifikacije (taksonomij in podatkov o podatkih) zmanjšuje hitrost dostopa do informacij, slabo strukturirane informacije pa onemogočajo učinkovito obvladovanje delovnih procesov. Zaradi neustreznega vsebinskega uvrščanja informacij in označevanja stopnje $\mathrm{v}$ procesu priprave informacije se izgubljajo različice dokumentov in zapisov. Uporabniki pogosto ne vedo, kje in kaj iskati ali kako iskati informacije, kar sproža dodatne postopke nove izmenjave in dodatno obremenitev komunikacijskih kanalov.

Stopnjo obvladovanja informacij otežujejo zahteve po njihovem varovanju, ko je optimalno dodeljevanje dostopnih pravic in spoštovanje pravila potrebe po vedenju, brez opredeljenih procesov in informacijskih potreb, časovno zahtevno. Analiza uporabe sistema portal je pokazala, da se pri iskanju informacij uporabniki raje omejijo na ožje teme in redko posegajo v zahtevnejša iskanja morebitnih informacij.

Raziskava kaže na povezavo med zrelostjo, obvladovanjem in operativnim tempom. Odprt ostaja niz vprašanj, ki so pomembna tako za osebe, odgovorne za obvladovanje informacij pri urejanju tega področja, kot tudi za osebe, odgovorne za informacijsko-komunikacijsko tehnologijo. Vprašanja odnosa do delitve informacij, izboljšanja hitrosti dostopa in kakovosti informacij, obsega in prednostnega vrstnega reda v avtomatski obdelavi ter prilagajanja spremembam v procesu so le del obširnega seznama vprašanj modernega obvladovanja informacij. Obvladovanje informacijskih potreb je med prednostnimi elementi, saj njihova opredeljenost vpliva na vse elemente operativnih procesov.

Za številna vprašanja je mogoče najti rešitve le z visoko ravnijo obvladovanja informacij, ki vključuje vse elemente zmogljivosti, od procesa, standardov in vodenja do usposobljenih kadrov.

\section{UGOTOVITVE IN PREDLOGI}

Odprtih je veliko možnosti na področjih izboljšanja procesov, vzpostavitve in uvedbe politik in standardov, spremljanja, izvajanja in izboljšanja storitev ter orodij informacijske tehnologije. Področje obvladovanja informacij ima v SV še veliko izzivov pri postavitvi sistema, ki bo zagotavljal relevantne informacije in s svojimi predlogi pripomogel $\mathrm{k}$ integraciji storitev, učinkoviti izmenjavi informacij ter izboljšanju sodelovanja. $\mathrm{S}$ tem bo zagotovljeno hitrejše in uspešnejše delo, $\mathrm{z}$ manj napakami in večjo kakovostjo informacij pa bodo odločitve vodstva lahko optimalne.

Obvladovanje informacij pomeni, da so informacijske potrebe jasne in zagotovljene $\mathrm{v}$ procesih dela in odločanja, in sicer na način, ki omogoča učinkovito in uspešno 
izvedbo nalog. Zahteve uporabnikov je mogoče izpolniti le s primernimi rešitvami, te pa so v soodvisnosti s številnimi dejavniki koncepta sodelovanja (ustreznost informacij in komunikacijskih poti, preprostost za uporabo, prilagojenost za posebne situacije in druge) ter dejavniki celovitega obvladovanja informacij.

Postavitev informacijskih sistemov in njihova prenova ali integracija zahtevata jasnost procesov in uporabniških informacijskih potreb. Enako velja za spremembe sistemov in njihovo opuščanje.

Če je obvladovanje informacij organizacijsko nepravilno umeščeno oziroma del organizacije tega področja ne podpira, rezultati ne morejo biti optimalni. Celovito obvladovanje informacij mora biti postavljeno $\mathrm{v}$ celoto tudi $\mathrm{v}$ organizacijskem smislu, odločanje pa umeščeno na ustrezno raven v organizaciji.

Kakovost in obseg informacij, ki so na voljo uporabnikom za izvajanje aktivnosti $\mathrm{v}$ sistemih, in storitve informacijske tehnologije vplivajo na učinkovitost procesov in kakovost odločanja. V preteklosti je bilo veliko virov namenjenih tehnološkim rešitvam, manj pa kakovosti obvladovanja informacij. Le s skladnim obvladovanjem informacij in razvojem informacijsko-komunikacijskih storitev je mogoče uresničevati poslanstvo obeh področij, da bo vplivalo na uspešno delovanje organizacije.

Enake informacije se po nepotrebnem vpisujejo, prepisujejo in potujejo po več sistemih - sporočilnem, portalnem, spletnem, mobilnem, papirnem ali govornem. Ko gre ista informacija skozi več sistemov, ki med seboj niso dovolj povezani oziroma niso združeni, je na koncu vprašljiva identičnost z izvirnikom. Ravno identičnost je ena večjih težav in hkrati izziv za izboljšanje obvladovanja informacij. Neprave informacije povzročajo napačne odločitve, otežujejo uporabnikom delo in povečujejo porabo človeških, finančnih in materialnih virov.

Združitev sedanjih informacijskih sistemov je prihodnost, ki se ji organizacije ne bodo mogle izogniti, ne glede na to, na kateri stopnji zrelosti obvladovanja informacij so. Povezava procesov, ljudi in tehnologije bo celovita, ko bo priprava vsebovala vse ključne elemente, od analize procesov, delovnih tokov, informacijskih potreb uporabnikov do njihovega usposabljanja.

Med številnimi vprašanji je treba določiti ključne rešitve, skladno z najboljšo prakso in prednostnim vrstnim redom:

- organizacija naj si skupaj z vodilnimi odgovori na vprašanje o morebitnih koristih, ki jih obvladovanje informacij prinaša; odgovori naj si tudi na vprašanje o organizaciji, procesu in vlogi v njegovem izvajanju;

- v zvezi s pričakovanji naj si postavi cilje in merila, ki bodo pozitivno vplivali na zadovoljstvo uporabnikov informacij in raven podpore odločanju; 
- nujna sta razmejitev pristojnosti za področja obvladovanja informacij in informacijsko-komunikacijske tehnologije ter izboljšanje sodelovanja z vidika izboljšanja podpore zahtevam procesov in uporabnikov;

- procesi obvladovanja informacijske tehnologije naj se preuredijo tako, da bo mogoče produkte obvladovanja informacij umestiti v informacijsko arhitekturo;

- področje celovitega obvladovanja kakovosti naj se preoblikuje tako, da bo vsebovalo tudi informacijske potrebe, kot jih narekujejo modeli procesov, da bo mogoče učinkovito obvladovati informacije v celotnem življenjskem ciklu, vzpostaviti in uvesti nujne standarde in politike obvladovanja informacij, vključno z varovanjem informacij, upravljanjem podatkov in vodenjem zapisov;

- z ustreznimi načrti obvladovanja informacij in rednim usposabljanjem, ki bo postopno privedlo tudi do kakovostnih rešitev obvladovanja znanja, naj se za vse enote intenzivira souporaba informacij.

$\mathrm{S}$ prehodom na storitveno orientirano arhitekturo, integracijske standarde in tehnologije se odpirajo številne nove možnosti, ki obljubljajo lažjo pot k uresničevanju ciljev obvladovanja informacij. Ne glede na nove tehnološke možnosti pa ostaja odprto vprašanje opredeljevanja informacijskih potreb in arhitekture informacij za nenehno prilagajanje in potrebe poslovanja tudi na sedanjih izdelkih ter storitvah informacijske tehnologije.

1. Butler, S., 2006. Acquisition Support to the Operational Arena Operational Arena. 11thICCRTS, www.dodccrp.org/events/11th_ICCRTS/html/papers/007.pdf, 11. 5. 2014.

2. Choo Chun Wei, 1997. Organizations as "Information-use Systems" A Process Model of information Management. Amsterdam: PrimaVera Working paper 97-17, Universiteit van Amsterdam.

3. Choo Chun Wei, 2002. Information Management for the Intelligent Organization, "ASIS Monograph, 1st edition 1995, 2nd edition 1998, 3rd edition 2002. eBook edition 2012. Medford: Information Today, inc.

4. Davenport, T., Prusak, L., 2000. Working knowledge: how organizations manage what they know. Cambridge: MA: Harvard Business School Press.

5. Direktiva za upravljanje z informacijami, 2010. Interni dokument MO RS.

6. Dovč, D., 2013. Magistrsko delo Obvladovanje informacij in omrežno sodelovanje, Kranj: Fakulteta za organizacijske vede.

7. Gurteen, D., 1999. Creating a Knowledge Sharing Culture, http://www.gurteen.com/ gurteen/gurteen.nsf/id/ksculture, 11. 5. 2014.

8. Leigh, J., 2012. The Most Important Person in Your Organization Is Not Who You Think It Is, http://allthingsd.com/20110712/the-most-important-person-in-yourorganization \%E2\%80\%A6is-not-who-you-think-it-is/, 11. 5. 2014.

9. Linderman, M., Siegel, B., Ouellet, D., Brchacek, J., Haines, S., Chase, G., O 'May, J., 2005. A Reference Model for Information Management to Support Coalition Information Sharing Needs, http://www.dtic.mil/docs/citations/ADA464244, 11. 5. 2014.

10. McNulty, C., 2004. Human and Organizational Implications of NEC. 1. Nato NEC Conference, Norfolk.

11. Nagelj, M., 2011. Izzivi strategije razvoja storitev informacijsko-komunikacijske tehnologije Sodobni vojaški izzivi 13/št. 4. 
12. Nagelj, M., 2011. Mrežne tehnologije in transformacija organizacije, Sodobni vojaški izzivi $13 /$ st. 1 .

13. Nato Joint doctrine note 4/06information management JDN IM, 2006. Joint Doctrine, Publications (JDPS)/Joint Warfare Publications (JWPS).

14. Nato NIMA IKM Introduction, 2010. Interni dokument Nato NIMA.

15. Pontius, R., Whitehead, S., 2010. Update on U.S. C2-related Efforts and Initiatives, NEC conference, http://www.docstoc.com/docs/77480713/Nato-Network-Enabled-CapabilityConference-Nnec-2010-ALLIED-COMMAND-TRANSFORMATION-NATO-NETWORK, 11. 5.2014

16. Robertson, J., 2005. 10 principles of effective information management, http://www. steptwo.com.au/papers/kmc_effectiveim/index.html, 11. 5. 2014

17. US Army Centre for Lessons Learned (CALL). http://usacac.army.mil/cac2/call/, 11. 5. 2014.

18. Van Domselaar, B., 2010. NIMA's Approach to Enable Information Sharing and Collaboration, NNEC konference.

19. Wortel, L., Grant, T., Soeters, J., 2007. Netherlands Defence Academy, C2 Systems \& Information Sharing in Cross-Cultural Context, http://www.dodccrp.org/events/12th ICCRTS/, 11. 5. 2014. 